\title{
Definitive radiotherapy with concurrent oncothermia for stage IIIB non-small-cell lung cancer: A case report
}

\author{
SEUNG-GU YEO \\ Department of Radiation Oncology, Soonchunhyang University College of Medicine, \\ Soonchunhyang University Hospital, Cheonan 330-721, Republic of Korea
}

Received September 12, 2014; Accepted June 3, 2015

DOI: $10.3892 /$ etm.2015.2567

\begin{abstract}
Hyperthermia enhances the susceptibility of tumors to radiotherapy (RT) and chemotherapy. Oncothermia, also known as electro-hyperthermia, is a new treatment modality developed to overcome the problems of traditional hyperthermia by selectively delivering energy to the malignant tissues. The present study reports the outcome of combined oncothermia and RT in a 75-year-old patient with stage IIIB non-small-cell lung cancer (NSCLC). Due to the advanced age and the performance status of the patient, the combination of systemic chemotherapy and RT was deemed infeasible; therefore, the patient instead decided to undergo oncothermia concurrently with definitive RT. The RT was administered at a dose of 64.8 Gy in 36 fractions using a three-dimensional conformal plan technique. Oncothermia was started concomitantly with RT and was performed for 60 min per session, two sessions per week, for a total of 12 sessions. No severe toxicities developed, with the exception of mild odynophagia, which resolved soon after the treatments. Follow-up computed tomography showed complete tumor response, and the patient was alive with no evidence of the disease 18 months after the completion of the treatment. In conclusion, the present case report suggests that oncothermia combined with RT, with the former possessing radiosensitizing potential and no additional toxicities, may be a promising alternative for advanced-age and/or frail patients with locally advanced NSCLC.
\end{abstract}

\section{Introduction}

Lung cancer is the leading cause of cancer-related mortality (1). The majority of patients with lung cancer present with advanced-stage disease. According to the Surveillance,

Correspondence to: Dr Seung-Gu Yeo, Department of Radiation Oncology, Soonchunhyang University College of Medicine, Soonchunhyang University Hospital, 31 Soonchunhyang 6-gil, Dongnam-gu, Cheonan 330-721, Republic of Korea

E-mail: md6630@schmc.ac.kr

Key words: non-small-cell lung cancer, radiotherapy, oncothermia, hyperthermia
Epidemiology and End Results database (2), 65\% of non-small-cell lung cancer (NSCLC) cases are diagnosed at stage IIIB or IV. Curative and palliative treatments are provided for NSCLC patients at stage I-IIIA and IV, respectively. With stage IIIB NSCLC, some eligible patients receive curative-intent treatments, which combine radiotherapy (RT) and chemotherapy; however, the overall 5-year survival rate remains at $3-8 \%(3,4)$.

With regard to locally advanced NSCLC, sequential chemoradiotherapy (CRT) was first compared with prior RT alone. Following the identification of the superior outcomes of sequential CRT, concurrent CRT was compared with sequential CRT (5). A meta-analysis demonstrated a significant advantage of concurrent CRT in overall survival, due to increased locoregional disease control (6); however, a proportion of patients with locally advanced NSCLC still receive RT alone, as they are unsuitable for combined CRT due to advanced age, underlying diseases, poor reserve of critical organs or low-grade performance. In addition, certain patients are reluctant to receive systemic chemotherapy due to excessive concern over its toxicity.

Hyperthermia is an old form of cancer therapy that involves attacking the malignant disease by administering heat in various ways. It has been usually applied as an adjunct to an already established treatment modality (7); however, medical and technical problems have prevented its wide acceptance. It is suggested that oncothermia, a new concept of hyperthermia, can overcome these shortcomings (8). The present study records the case of a patient with stage IIIB NSCLC who received concurrent oncothermia and definitive RT.

\section{Case report}

A 75-year-old male visited the Soonchunhyang University Hospital (Cheonan, Republic of Korea) presenting with hoarseness. He was an active smoker with a 50-pack-year history. Simple chest radiography showed a mass-like lesion in the left upper lobe. Computed tomography (CT) revealed a $2.6-\mathrm{cm}$ irregular mass with peripheral enhancement in the left upper lobe abutting the descending thoracic aorta. The left lower paratracheal lymph node was enlarged and appeared to have extranodal extension and recurrent laryngeal nerve invasion. The endobronchial lesion was not detected by flexible bronchoscopy. Pathological examination by percutaneous needle 


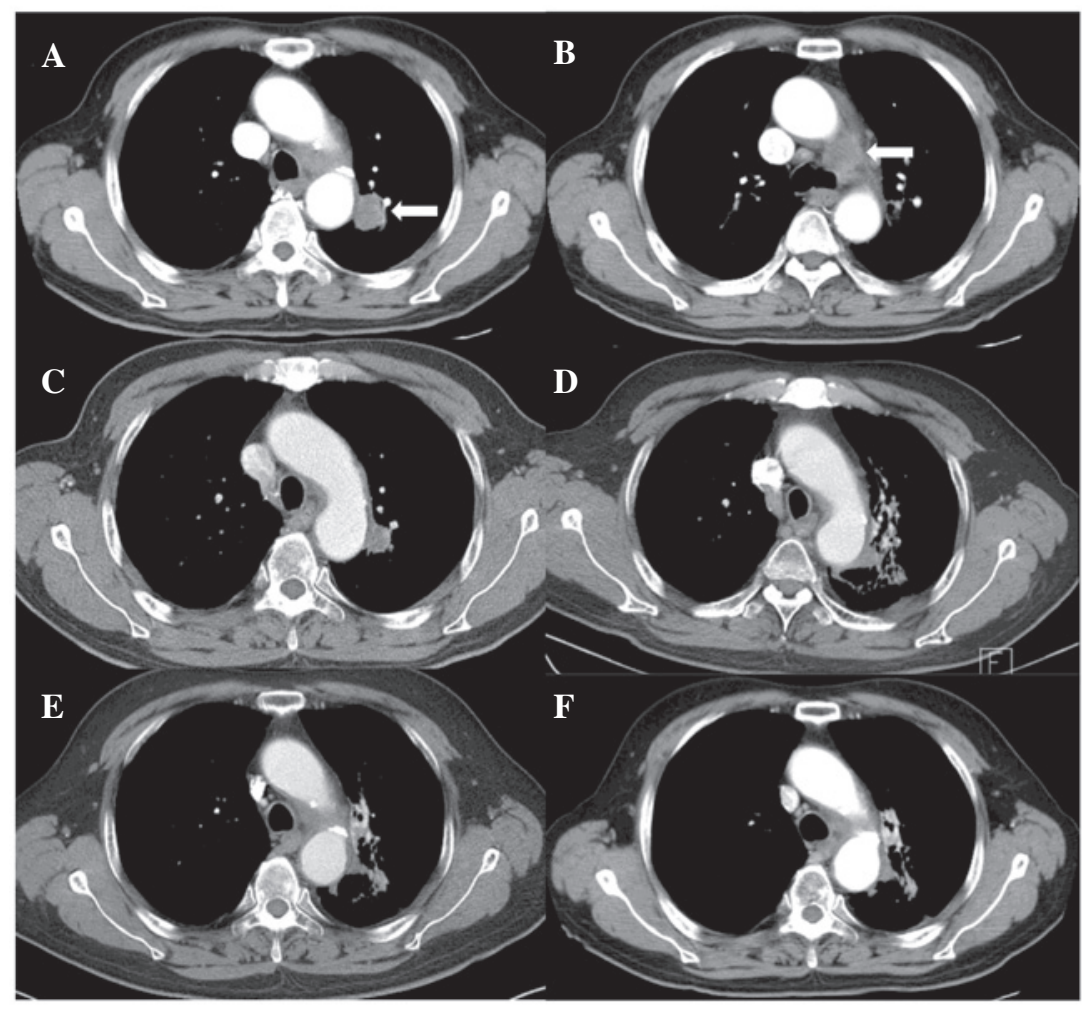

Figure 1. Pre- and post-treatment axial computed tomography images. (A and B) Pretreatment: (A) A 2.6-cm lung tumor in the left upper lobe (arrow) and (B) an enlarged left lower paratracheal lymph node (arrow). (C-F) Post-treatment: Gradual tumor regression and appearance of radiation pneumonitis/fibrosis at (C) 3, (D) 6, (E) 9 and (F) 15 months after treatment.

biopsy revealed a poorly differentiated adenocarcinoma. Positron emission tomography-CT showed an increased ${ }^{18} \mathrm{~F}$-fluorodeoxyglucose uptake in both the primary mass and the lymph node. The pretreatment serum level of carcinoembryonic antigen was $2.65 \mathrm{ng} / \mathrm{ml}$. Pulmonary function testing showed a forced expiratory volume in $1 \mathrm{sec}$ of 2.48 liters (78\%). A whole-body bone scan, brain magnetic resonance imaging and positron emission tomography-CT showed no evidence of distant metastasis. The TNM clinical stage was determined as T4N2M0 (stage IIIB) (9). The present study was conducted in accordance with the guidelines of the Institutional Review Board and informed consent was obtained from the patient.

The patient was deemed unfit for chemotherapy due to advanced age and an Eastern Cooperative Oncology Group performance scale score of 2. Definitive RT was scheduled and the patient agreed to undergo oncothermia concurrently with RT. During the RT simulation, the patient was immobilized in the supine position, with the arms above the head, in a vacuum-bag restriction system (Vac-Lock; CIVCO Medical Solutions, Kalona, IA, USA). CT was performed using a 16-slice CT scanner (Brilliance CT Big Bore; Philips Medical Systems, Cleveland, OH, USA) and intravenous contrast. Only the gross tumor volume, including the primary lesion and involved lymph node, was included in the RT target; elective nodal irradiation was not considered. A three-dimensional conformal plan was created using the Eclipse treatment planning system (Varian Medical Systems, Inc., Palo Alto, CA, USA) and 15-MV photons. The RT fractionation scheme was $64.8 \mathrm{~Gy}$ in 36 fractions. RT was performed using a Novalis Tx system (Varian Medical Systems, Inc./BrainLab, Feldkirchen, Germany).

Oncothermia was carried out using the EHY 2000 device (Oncotherm GmbH, Troisdorf, Germany). A 30-cm-diameter electrode was applied using the position of the RT simulation target. Oncothermia was performed for $60 \mathrm{~min}$ per session, two sessions per week, for a total of 12 sessions. The applied power was gradually and linearly increased from 60 to $140 \mathrm{~W}$, depending on the tolerance of the patient.

Planned treatments of RT combined with oncothermia were completed without interruption. Acute toxicity was limited to mild odynophagia, which subsided with conservative management. No skin reaction developed. Follow-up CT (Fig. 1) showed a complete tumor response along with signs of radiation pneumonitis and fibrosis around the treated region; however, the patient developed no specific associated symptoms. There was an improvement in the presenting symptom of hoarseness and the patient was alive without any evidence of the disease at 18 months after treatment.

\section{Discussion}

Hyperthermia has the ability to kill cancer cells as a direct response to heat and, more importantly, render cancer cells more susceptible to RT and certain chemotherapeutic drugs (10). The synergistic mechanisms of hyperthermia and RT include inhibition of lethal or sublethal damage repair, cell cycle sensitivity and tumor oxygenation (11). The clinical response rates have been approximately doubled from $25-35 \%$, with RT alone, to $50-70 \%$ with combined RT and hyperthermia (12). 
Seventeen randomized trials of hyperthermia have been performed, primarily in patients with sarcoma and cervical, breast and bladder cancer. Following the addition of hyperthermia to the standard therapy, improvement in local control and/or patient survival was achieved $(12,13)$; however, several challenges must be overcome before hyperthermia can be established as a standard practice in oncology $(14,15)$.

The physical objective of hyperthermia is to achieve tumor temperatures of $40-45^{\circ} \mathrm{C}$ and to maintain that temperature for $1 \mathrm{~h}$. This is accomplished using non-ionizing electromagnetic or ultrasound radiation; however, heating tumor volumes selectively, precisely and uniformly is technically challenging $(7,12)$. Common toxicities include superficial tissue burns, subcutaneous fat necrosis or infection from the use of a catheter to monitor the intratumoral temperature (12).

The recent development of oncothermia, also known as electro-hyperthermia, has led to a renewed interest in the oncologic treatment modality that is hyperthermia. Oncothermia is a precise impedance-matched system based on capacitive coupling (7). Due to the high ion concentration near malignant cells and the low impedance of tumors (increased metabolism), the modulated radiofrequency current flow $(13.56 \mathrm{MHz})$ and absorption of energy are concentrated in tumor tissues, particularly in the extracellular matrix and the membranes of malignant cells (7). Not only the heating but also the electric field itself is efficacious (non-thermal effects); therefore, the tumor temperature required by oncothermia is lower than that required by conventional hyperthermia. Traditional hyperthermia relies on temperature, while oncothermia is energy dose-dependent (7). The complications reported have been restricted to a small erythema $(<8 \%)(8)$, and the contraindications are few, with the exception of the existence of a pacemaker or metallic implants/replacements in the treated area. Lung and liver tumors are known to be unsuitable candidates for conventional hyperthermia, due to the fact that they have their own cooling systems, such as air ventilation and high blood flow, respectively. On the contrary, tumors located in the aforementioned organs have been shown to be good therapeutic targets for oncothermia $(8,16)$. The present case report supports this suggestion by demonstrating the favorable outcome in an NSCLC patient treated with combined RT and oncothermia.

The results of RT alone in early-stage NSCLC have been considerably improved following the introduction of stereotactic body RT $(17,18)$, but the survival time of patients with locally advanced NSCLC remains poor (median survival, $\leq 1$ year) following conventional RT alone (5). By contrast, a randomized trial comparing concurrent CRT with sequential CRT for locally advanced NSCLC patients showed that the median survival time associated with concurrent CRT was 17 months (19). Locoregional progression has been shown to significantly decrease and distant progression to remain the same (6); however, numerous patients with locally advanced NSCLC receive RT alone for various reasons, such as advanced age, comorbidities or poor performance status. Historically, older cancer patients have been undertreated, which has made elderly patients with stage III NSCLC less likely to be selected for concurrent CRT (20). Furthermore, integration of concurrent CRT has been accompanied by increased toxicities, particularly esophageal complications. In a previous study, the incidence rate of severe (grade III or IV) esophageal toxicity was shown to have increased to $18 \%$ (6). Hematological and pulmonary toxicities are also increased by combined chemotherapy. Despite the fact that hyperthermia is also synergistic with chemotherapy and triple-modality treatment is feasible (21), the present case report suggests that combined oncothermia with RT, with the former having radiosensitizing potential and no additional toxicities, may be a promising alternative for advanced-age and/or frail patients with locally advanced NSCLC.

\section{Acknowledgements}

The present study was supported by the Soonchunhyang University Research Fund.

\section{References}

1. Jung KW, Won YJ, Kong HJ, Oh CM, Lee DH and Lee JS: Prediction of cancer incidence and mortality in Korea, 2014. Cancer Res Treat 46: 124-130, 2014.

2. William WN Jr, Lin HY, Lee JJ, Lippman SM, Roth JA and Kim ES: Revisiting stage IIIB and IV non-small cell lung cancer: Analysis of the surveillance, epidemiology and end results data. Chest 136: 701-709, 2009.

3. Goldstraw P, Crowley J, Chansky K, Giroux DJ, Groome PA, Rami-Porta R, Postmus PE, Rusch V and Sobin L: International Association for the Study of Lung Cancer International Staging Committee; Participating Institutions: The IASLC Lung Cancer Staging Project: Proposals for the revision of the TNM stage groupings in the forthcoming (seventh) edition of the TNM Classification of malignant tumours. J Thorac Oncol 2: 706-714, 2007.

4. Russell K, Healy B, Pantarotto J, Laurie SA, MacRae R, Sabri E and Wheatley-Price P: Prognostic factors in the radical nonsurgical treatment of stage IIIB non-small-cell lung cancer. Clin Lung Cancer 15: 237-243, 2014.

5. Laine AM, Westover KD and Choy H: Radiation therapy as a backbone of treatment of locally advanced non-small cell lung cancer. Semin Oncol 41: 57-68, 2014.

6. Aupérin A, Le Péchoux C, Rolland E, Curran WJ, Furuse K, Fournel P, Belderbos J, Clamon G, Ulutin HC, Paulus R, Yamanaka T, et al: Meta-analysis of concomitant versus sequential radiochemotherapy in locally advanced non-small-cell lung cancer. J Clin Oncol 28: 2181-2190, 2010.

7. Hegyi G, Szigeti GP and Szász A: Hyperthermia versus oncothermia: Cellular effects in complementary cancer therapy. Evid Based Complement Alternat Med 2013: 672873, 2013.

8. Andocs G, Szasz O and Szasz A: Oncothermia treatment of cancer: From the laboratory to clinic. Electromagn Biol Med 28: 148-165, 2009.

9. Edge SB, Byrd DR, Compton CC, Fritz AG, Greene FL and Trotti A (eds): AJCC Cancer Staging Manual. 7th edition. Springer, New York, NY, 2010

10. Coffey DS, Getzenberg RH and DeWeese TL: Hyperthermic biology and cancer therapies: A hypothesis for the 'Lance Armstrong effect'. JAMA 296: 445-448, 2006.

11. Roti Roti JL: Cellular responses to hyperthermia (40-46 degrees C): Cell killing and molecular events. Int J Hyperthermia 24: 3-15, 2008.

12. Halperin EC, Brady LW, Perez CA and Wazer DE (eds.): Perez and Brady's Principles and Practice of Radiation Oncology 6th edition. Lippincott Williams \& Wilkins, Baltimore, MD, 2013.

13. van der Zee J, González González D, van Rhoon GC, van Dijk JD, van Putten WL and Hart AA; Dutch Deep Hyperthermia Group: Comparison of radiotherapy alone with radiotherapy plus hyperthermia in locally advanced pelvic tumours: A prospective, randomised, multicentre trial. Lancet 355: 1119-1125, 2000.

14. Sauer R, Creeze H,Hulshof M,Issels R and Ott O; Interdisciplinary Working Group for Clinical Hyperthermia (Atzelsberg Circle) of the German Cancer Society and the German Society of Radiooncology: Concerning the final report 'Hyperthermia: A systematic review' of the Ludwig Boltzmann Institute for Health Technology Assessment, Vienna, March 2010. Strahlenther Onkol 188: 209-213, 2012. 
15. Wild C: Should hyperthermia be included in the benefit catalogue for oncologic indications? Commercial interests are presumed behind the editorial of R. Sauer et al: Strahlenther Onkol 189: 81-86, 2013.

16. Szasz A: Current status of oncothermia therapy for lung cancer. Korean J Thorac Cardiovasc Surg 47: 77-93, 2014.

17. Kim MJ, Yeo SG, Kim ES, Min CK and Se An P: Intensity-modulated stereotactic body radiotherapy for stage I non-small cell lung cancer. Oncol Lett 5: 840-844, 2013.

18. Yeo SG and Kim ES: Efficient approach for determining four-dimensional computed tomography-based internal target volume in stereotactic radiotherapy of lung cancer. Radiat Oncol J 31: 247-251, 2013.
19. Curran WJ Jr, Paulus R, Langer CJ, Komaki R, Lee JS, Hauser S, Movsas B, Wasserman T, Rosenthal SA, Gore E, Machtay M, Sause W and Cox JD: Sequential vs. concurrent chemoradiation for stage III non-small cell lung cancer: Randomized phase III trial RTOG 9410. J Natl Cancer Inst 103: 1452-1460, 2011.

20. Bayman N, Blackhall F, McCloskey P, Taylor P and Faivre-Finn C: How can we optimise concurrent chemoradiotherapy for inoperable stage III non-small cell lung cancer? Lung Cancer 83: 117-125, 2014.

21. Westermann AM, Jones EL, Schem BC, van der Steen-Banasik EM, Koper P, Mella O, Uitterhoeve AL, de Wit R, van der Velden J, Burger C, van der Wilt CL, et al: First results of triple-modality treatment combining radiotherapy, chemotherapy and hyperthermia for the treatment of patients with stage IIB, III and IVA cervical carcinoma. Cancer 104: 763-770, 2005. 